\title{
CESÁREA ELECTIVA: PREFERENCIA MATERNA
}

\section{ELECTIVE CESAREAN SECTION BY MATERNAL DECISION}

Jorge Ybaseta - Medina ${ }^{1, a}$

1. Universidad Nacional San Luis Gonzaga de Ica, Perú.

a. Director de la Revista Médica Panacea.

La vía fisiológica de finalización de un embarazo es la vaginal. El parto no es un proceso patológico, por lo que en principio no requiere de intervención quirúrgica generalmente, debiendo evolucionar espontáneamente según las leyes de la naturaleza (1).

La operación cesárea se sigue incrementada a nivel mundial y se asocia a una mayor morbilidad materna, generalmente con beneficios no cuantificados para el producto de la gestación (1). Sin embargo, dado el incremento del riesgo al que madre e hijo están sometidos, y paralelamente al desarrollo científico y tecnológico, la obstetricia ha ido incrementando el número de acciones tanto de control del bienestar como de finalización del embarazo, con el fin de mejorar de forma progresiva los resultados perinatales $(1,2)$.

La cesárea electiva es otra opción hoy en día preferida sobre el parto vaginal, por existir ventajas médicas así también es posible por conveniencias, el fenómeno de las cesáreas sin indicación obstétrica, médica o fetal, resalta la importancia de establecer protocolos basados en evidencias que permitan homogeneizar el juicio clínico en cada tipo de nacimiento en base a sus riesgos y beneficios particulares (3).

La controversia en torno a la operación cesárea se deriva de la existencia de dos vías por las cuales se puede resolver un parto, y el especialista debe juzgar en cada caso particular cuál de estas dos vías representa lo mejor para sus dos pacientes, la madre y el feto. Cuando el cálculo riesgo-beneficio se encuentra en un estado de equilibrio dinámico, surgen los dilemas éticos relativos a la indicación de la cesárea electiva (2).

Resulta contrario a la razón que una mujer pueda decidir en algunas realidades si quedarse o no embarazada, si interrumpir o no ese embarazo, pero sin embargo se le niega la elección informada sobre el método del parto (2).

Actualmente al compararse los indicadores negativos materno perinatales de las dos vías del parto sus resultados no tienen diferencias significativas, con esto se entiende que resulta igual de riesgo cualquier vía de nacimiento para el binomio, este hallazgo llama a reflexión si es aceptable tomar en cuenta la preferencia materna. El principio de autonomía del paciente está llevando a muchas unidades de obstetricia a experimentar la demanda de las cesáreas por petición materna, indicación por supuesto que sería formal si hubiese un consentimiento informado con respeto a los riesgos y beneficios del procedimiento, si se respetara la autonomía del Gineco-Obstetra para ejercer de acuerdo a prácticas médicas estándares y aceptados $(2,3)$.

La discusión del respeto ilimitado que corresponde al principio de autonomía de la paciente sobre la solicitud de la cesárea programada en un embarazo con condiciones para ser un parto vaginal y como el ginecólogo debe responder a la paciente que lo solicita son situaciones que constituyen dilemas éticos que crean perplejidad en el médico.

Considerando la información disponible hoy en día, las cesáreas sin indicación médica u obstétrica no deberían ser ofrecidas a la mujer, en instituciones públicas no se contempla que la gestante elija la vía del parto, en el futuro es seguro que se siga revisando sobre cesárea a petición del paciente la misma que debe estar guiada por los principios éticos de autonomía, beneficencia, no maleficencia y justicia. 


\section{REFERENCIA BIBLIOGRAFICAS}

1. Urquizo Vilca Y. Frecuencia del parto vaginal en pacientes con cesárea previa y sus principales complicaciones materno-perinatales en el Hospital III Goyeneche entre los años 2008 al 2013. [Tesis para optar el título profesional de médico cirujano]. Universidad Nacional de San Agustín Arequipa. Facultad de Medicina Humana; 2014. 50 p.

http://repositorio.unsa.edu.pe/bitstream/handle /UNSA/4310/MDurviyg.pdf? sequence=1\&isAllo wed $=y$
2. Fernando Conde Fernández. La cesárea una perspectiva bioética. Academia de Ciencias e Ingenierías de Lanzarote: España; 2009 https://int.search.myway.com/search/GGmain.jht $\mathrm{ml}$

3. Besio R Mauricio. Cesárea versus parto vaginal.: Una perspectiva ética. Rev. méd. Chile [Internet]. 1999 Sep [citado 2018 Ago 30]; 127(9): 1121-1125. Disponible en:

https://scielo.conicyt.cl/scielo.php?script=sci_artt ext\&pid=S0034-98871999000900014\&lng=es. http://dx.doi.org/10.4067/S0034-988719990009 00014. 